\title{
A Study on the Productivity in Coastal Waters by means of the Radio.carbon
}

\author{
by \\ Y. Miyake, K. Kigoshi, Y. Sugiura and K. Saruhashi \\ Meteorological Research Institute \\ (Received April 19, 1954)
}

\begin{abstract}
It may be said that the method using the radio-carbon is the best among others for measuring the oceanic productivity now. For the purpose to check and improve this method, the gross production of coastal waters was studied. The procedure was almost the same as that of E. S. NIELSEv. However, the direct measurement of the radio-carbon fixed in phyto-planktons with G-M counter was standardized by measuring ionization current in the carbon dioxide gas by Lauritsen electroscope. As the results of observations of coastal waters, it was ascertained that the diurnal change in the gross production was proportional to that of the solar radiation. Also it was found that the influence of the respiration of phyto-planktons and the wall effect of vessels could be negligible. In the same time, the total amount of phyto-planktons was determined as gaseous carbon dioxide by ignition. The simultaneous comparison was made between the productivity values by the radio-carbon method and the dissolved oxygen method for same samples and the considerable difference was found between them.
\end{abstract}

\section{Introduction}

Needless to say, of the great roles of living matter in the geochemical cycle of the carbon, the metabolism of the carbon by marine phyto-planktons is the most important. The amount of organic compounds expressed in gram atoms of the carbon which are produced in unit volume of sea water in unit time is called the "gross production" or "primary production". This is the result of fixation of the carbon dioxide by photo-synthesis in phyto-planktons. The "net production" is obtained by deducting the amount of simultaneous decomposition of organic matter from the gross production. The decomposition takes place through the respiration of living matter or the oxidation of organic compounds etc. The productivity in the oceans is mainly decided by that of phyto-planktons and the productivity value has been usually estimated by the amount of consumption or reproduction of nutrient matter or the dissolved oxygen and also by the quantita. tive determination of phyto-planktons in the sea.

Depending on these indirect methods RILEY [1] and SeIwell [2] estimated the mean net production in the whole ocean and they obtained the value of $375 \mathrm{~g} / \mathrm{m}^{2}$, year for it. Recently, direct measurement was developed by E. S. NIELSEN [3] during the cruise of "Danish Deep Sea Expedition" aboard the observation ship "Galathea". He used the radio-carbon as a tracer of the photo-synthesis in sea water and obtained $55 \mathrm{~g} / \mathrm{m}^{2} /$ year as the mean net production of the ocean. It is to be noted that Nielsen's value is considerably smaller than that estimated by RILEY 
and SEIWEIL. It may be said that Nielsen's procedure seems to be the best among the methods generally used until now, but it is still necessary to examine it in. order to get the actual productivity in the ocean.

The present authors intend to compare the productivity values in coastal sea waters observing simultaneously by, the oxygen method and the radio-carbon method.

Observations were done on the coast near Odawara, Kanagawa Prefecture, and at the Marine Biological Laboratory of Tokyo University situated at Aburatsubo, Kanagawa Prefecture respectively in August and September, 1953.

\section{Experimental}

Surface water collected in a canvas bucket is poured in glass stopped bottles, each containing only about $100 \mathrm{~m} l$ because of the difficulty in filtration due to the greater amount of suspending matter in coastal waters. $1 \mathrm{~m} l$ of aqueous solution of sodium carbonate containing $1 \sim 4 \mu c$ of ${ }^{14} \mathrm{C}$ was added to each bottle with a pipette. Bottles were suspended from a pier about $20 \mathrm{~cm}$ under the sea surface on a line at the same place of sampling. Beginning after sunrise, bottles: were brought into the laboratory at intervals until sunset, with a few bottles being left overnight until sunrise. Some bottles were covered with black tape to exclude light. The water was filtered to separate planktons after adding $5 \mathrm{~m} l$ of the aqueous solution of neutral formaline $(45 \%)$. Then, the amount of ${ }^{14} \mathrm{C}$ settled in planktons was determined quantitatively using Lauritsen electrometer and G-M counter from which gross production was calculated. On the other hand the amount of the total carbon contained in suspending matter in sea water was determined supposing that it is approximately the same as that contained in phytoplanktons. At the same time, the determination of the gross production was made by measuring the change of the dissolved oxygen by Winkler's method for separate bottles both dark and light. The solar radiation, water temperature, chlorinity, total inorganic carbon in sea water and $\mathrm{pH}$ were determined. The detailed procedure of each measurement is as follows.

\section{The preparation of the aqueous solution of sodium carbonate containing the radio-carbon}

The aqueous solution of sodium carbonate containing ${ }^{14} \mathrm{C}$ was prepared from the radio-active barium carbonate which had been supplied from Oak Ridge, USA. The carbon dioxide produced from the radio-active barium carbonate with perchloric acid was absorbed into the equivalent solution of sodium hydroxide. The solution of sodium carbonate thus obtained was diluted with distilled water and $1 \mathrm{ml}$ of the diluted solution which contains $1 \sim 2 \mu c$ of ${ }^{14} \mathrm{C}$ was enclosed in an am. pule. The concentration of sodium carbonate in an ampule was smaller than 0.003 mol per litre. Therefore, we could neglect the influence on $\mathrm{pH}$ by adding 1 or 2 $\mathrm{m} l$ of the sodium carbonate solution to $100 \mathrm{~m} l$ of sea water.

\section{Filtrations}

Suspending matter in sea water was filtered out on a filter paper (Toyo-Roshi, No. 4) mounted on a glass filter disc by suction. The effective surface area of a filter pad was $4.6 \mathrm{~cm}^{2}$. It took $15 \sim 20$ minutes to filter $100 \mathrm{ml}$ of sea water. Planktons collected on a filter pad was rinsed out with non-active sea water and after 
drying, it was exposed to the fume of hydrochloric acid as suggested by E.S. NIELSEN. In our experiment collodion filter was not used because of the difficulty in filtration. However, it was sure that all of phyto-planktons were filtered out completely on a filter pad used. We adopted the quantitative method to determine. ${ }^{14} \mathrm{C}$ by measuring the ionization current in carbon dioxide gas; therefore, there was no fear of underestimating the amount of ${ }^{14} \mathrm{C}$ due to the absorption of rays. caused by the intrusion of a part of planktons in the complicated net of filter fibres.

\section{The determination of the concentration of ${ }^{14} \mathrm{C}$ in the sodium carbonate solution.}

The aqueous solution of the sodium carbonate containing about $1 \mu \mathrm{c}$ of ${ }^{14} \mathrm{C}$ was diluted to $1 / 1000$ and $1 \sim 5 \mathrm{ml}$ of diluted solution was added to the aqueous: solution containing $1 / 100 \mathrm{~mol}$ of sodium carbonate free from ${ }^{14} \mathrm{C}$. Then, the carbonate ion in the latter was precipitated in a hot ammoniacal solution adding some. calcium chloride. The precipitated calcium carbonate was decomposed with perchloric acid and the carbon dioxide thus formed was introduced to the ionization chamber of Lauritsen electrometer which was specially designed for measuring the: ionization current in gaseous samples [4].

The correction was made on observed values of ionization current in order to. reduce it to the normal pressure value. By multiplying with the constant of the apparatus, the corrected ionization current gives the concentration of ${ }^{34} \mathrm{C}$ in the gaseous sample. Then the original concentration of ${ }^{14} \mathrm{C}$ could be computed taking into consideration the dilution done before the precipitation of calcium carbonate.

\section{The determination of ${ }^{14} \mathrm{C}$ settled in planktons}

Planktons with a filter paper were ignited in the oxygen air current passing through a tube containing hot cupric oxide and were converted completely into. carbon dioxide gas. The carbon dioxide gas was absorbed into $6 \mathrm{~N}$ aqueous solution of ammonia and after adding a proper amount of sodium carbonate, the calcium carbonate was precipitated while hot. The determination of ${ }^{14} \mathrm{C}$ in the precipitated calcium carbonate was done in the same manner as described in the preceding section. Thus, the quantity of ${ }^{14} \mathrm{C}$ contained in planktons seems to. ensure a higher accuracy than that with a G-M counter adopted by E.S. NIELSEN and it is more effective to get a correct value independent of the distribution of planktons on a filter paper. But, since the procedure to convert palnktons in the carbon dioxide gas is rather complicated, it may not be very convenient to treat. many samples within a short time. Therefore, we measured a factor $k$ in the next formula applying this method to a small number of samples.

$$
k={ }^{14} \mathrm{C} \text { content }(\mu c) / \beta \text { rays counts (per minute) with G-M counter }
$$

In Table 1 results of determination are given.

Using this $k$ value, the determinations of the amount of ${ }^{14} \mathrm{C}$ contained in filtered planktons were done for every sample from the observed intensity of rays with a G-M counter. G-M tube which was used. in our

Table 1.

\begin{tabular}{c|c|c}
\hline $\begin{array}{c}{ }^{14} \text { content } \\
\left(10^{-9} \text { curie }\right)\end{array}$ & c.p.m. & $k \times 10^{6}$ \\
\hline 3.15 & 1400 & 2.25 \\
2.22 & 1022 & 2.18 \\
2.79 & 1209 & 2.22 \\
3.34 & 1404 & 2.38 \\
\hline
\end{tabular}


laboratory had a thin mica end-window of $1.6 \mathrm{mg} / \mathrm{cm}^{2}$ and its effective counting area was $4.6 \mathrm{~cm}^{2}$.

\section{The determination of the total carbon contained in suspending matter in sea water}

The suspending matter in sea water which mainly consists of planktons and partly of detritus or soil particles was collected on a glass filter together with a small amount of the aluminium hydroxide and then it was converted into carbon dioxide by ignition. Aluminium hydroxide was prepared with the pure alum and ammonia, and the precipitate was washed several times repeatedly with distilled water through decantation. $100 \mathrm{mg}$ of aluminium hydroxide was added to $100 \mathrm{~m} l$ of sea water. As there was little change of $\mathrm{pH}$ in sea water with the addition of aluminium hydroxide there is no fear of precipitation of any carbonate. Added aluminium hydroxide was filtered through a tared glass filter and then weighed after drying on it. A portion of the precipitate was taken and ignited in a reaction tube as is used in elementary organic analysis. The carbon dioxide thus produced was absorbed through three tubes each containing $2.5 \mathrm{ml}$ of $1 / 20 \mathrm{~N}$ barium hydroxide solution and glass beads. After absorption was finished, the solution was titrated with $1 / 20 \mathrm{~N}$ hydrochloric acid to determine the absorbed amount of $\mathrm{CO}_{2}$.

\section{The determination of total carbonaceous matter, dissolved oxygen, chlorinity and solar radiation}

The total carbonaceous matter in sea water was determined by applying Conway's micro-diffusion method as was previously reported by one of the present authors [5]. The analysis on the dissolved oxygen was made by the ordinary Winkler's method. The chlorinity was determined by micro-analytical method [6]. The measurement of the diurnal change of the solar radiation was made by Robitzsch's pyrheliometer which was set near the observation place.

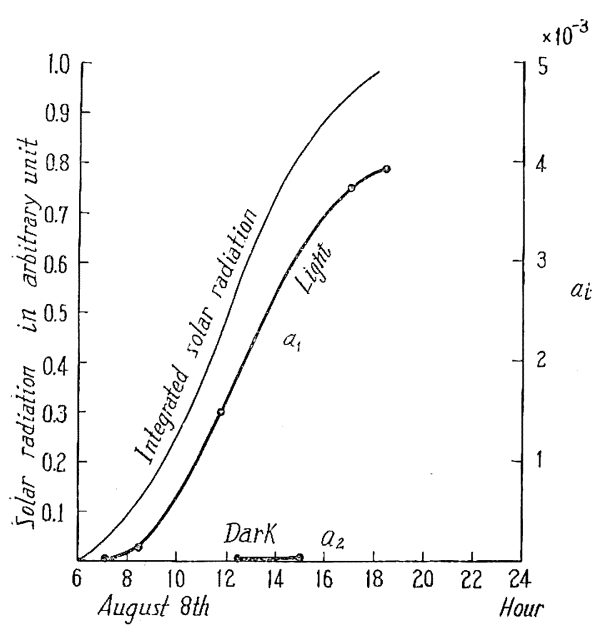

Fig. 1.

\section{Results of observation}

1) Results of observation made off coast of Odawara.

In Fig. 1, the results of observations made on the coast along Suruga Bay between Odawara and Kozu at an interval of three hours from 7h to $18 \mathrm{~h}$ on 10th August, 1953. The coordinate shows the integrated amount of gross production expressed in the ratio of the observed amount of ${ }^{14} \mathrm{C}$ which was settled in phyto-planktons during each three hours to that added to sea water originally. The amount of gross production was parallel to the integrated amount of solar energy up to the time of observation. Total carbon contained in suspending matter was 0.18 $\mathrm{mg}$ atoms $\mathrm{C} / l$, while the total carbonaceous 
matter in sea water was $2.0 \mathrm{mg}$ atoms $\mathrm{C} / l$. Therefore, the gross production per day was $8.0 \times 10^{-3} \mathrm{mg}$ atoms $\mathrm{C} / \mathrm{l} / \mathrm{day}$ and assuming that the total carbon contained in the suspending matter is approximately equal to that of phyto-plankton, it became $0.044 \mathrm{mg} \mathrm{C} / \mathrm{mg} \mathrm{C}$ phyto-plankton/day. We examined the effect of the size of bottles and comparison was done between bottles containing $100 \mathrm{~m} l$ and $500 \mathrm{~m} l$ under the same condition, but we found there was no difference beyond the experimental error.

2) The results of observation made at Aburatsubo.

Six bottles of sea water were collected at Aburatsubo, Miura Penninsula at $6 \mathrm{~h}$ on 26th September, 1953 and after adding $1 \sim 5 \mu c$ of ${ }^{14} \mathrm{C}$, the bottles were suspended in the sea. Each bottle was taken out every three hours in the day-time and ${ }^{14} \mathrm{C}$ entering into phyto-plankton by photo-synthesis was determined. As shown by the curve $a_{1}$ in Fig. 2, the in. crease in the ${ }^{14} \mathrm{C}$ amount was quite proportional to the solar radiation as in the case at Odawara.

On the other hand, five bottles containing the same water sample were kept in the sea under the same condition as mentioned above. After five hours, one of them was taken out and ${ }^{14} \mathrm{C}$ determination was done. The other four bottles were covered with black tape to

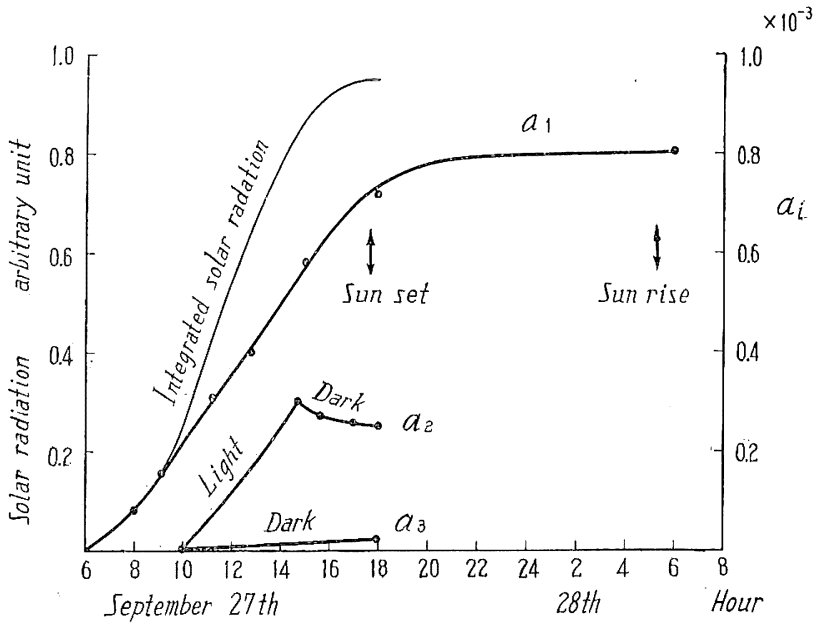

Fig. 2. prevent the solar radiation and dipped into the water again to examine the change. in the amount of ${ }^{14} \mathrm{C}$ once assimilated in phyto-planktons. As shown by the curve $a_{2}$ in Fig. 2, the decrease due to respiration was not clearly found. Therefore, within the experimental error, it may be said there is no evidence that the newly assimilated ${ }^{14} \mathrm{C}$ was liberated more easily by respiration than the carbon previously contained in the organic compounds. Simultaneously with the experiments mentioned above, the change in dissolved oxygen in sea water in light and dark bottles was measured (Fig. 3). From the observed values on the dissolved oxygen. we obtained the estimated value of $0.013 \mathrm{mg}$ atoms $\mathrm{C} / \mathrm{l} / \mathrm{day}$ as the gross production which is consiclerably higher than that obtained by ${ }^{14} \mathrm{C}$ experiments. The total carbonaceous matter in sea water used here was $2.0 \mathrm{mg}$ atoms $\mathrm{C} / l$ and the amount. of planktons represented as $\mathrm{C}$ was $0.10 \mathrm{mg}$ atoms $\mathrm{C} / \mathrm{l}$. According to $\mathrm{Mr}$. S. K. WADA, total number and species of planktons were as follows,

Table 2.

\begin{tabular}{lr|lr}
\hline \hline number & $26,500 / l$ & tintinoineans & $17 \%$ \\
diatoms & $80 \%$ & etc. & $1 \%$ \\
dinoflagellates & $2 \%$ & &
\end{tabular}




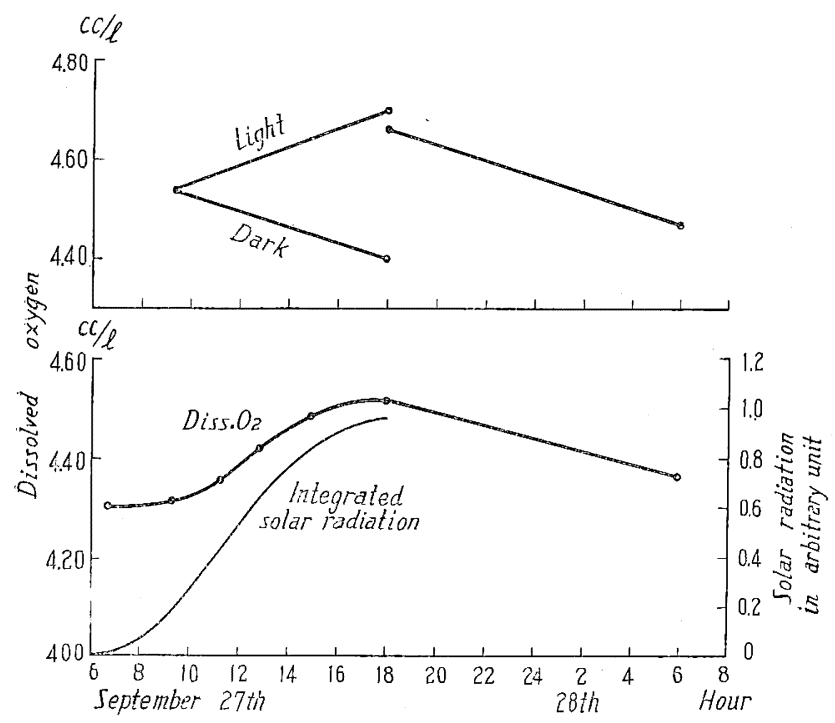

Fig. 3.

Assuming that the amount of carbon in the total suspended matter was approximately the same as that contained in phytoplankton, gross production per day becomes $1.6 \times 10^{-2}$ $\mathrm{mg}$ atoms $\mathrm{C} / \mathrm{mg} \mathrm{C}$ phytoplankton/day by ${ }^{i 4} \mathrm{C}$ method.

\section{Conclusion}

Concerning the procedure of the experiment, we could obtain satisfactory results. However, there are some fluctuations among the values observed with G-M counter, which are probably due to the anomalous distribution of planktons on a

filter pad. There is no fear of resulting great failure so far as the radio-carbon method of productivity measurement is concerned, but, if the newly assimilated carbon were released easily, important troubles would be brought about. On this point we could confirm that there was no fear of occurrence of such a special phenomenon. We found great difference in productivity values between the ${ }^{14} \mathrm{C}$ method and the oxygen method. The cause is unknown yet but we may suppose that it is probably due to the excess rate of oxygen metabolism besides the phytoplanktons in coastal sea waters.

Ackrowledgement- Authors wish to express their thanks to Mr. S. K. WADA who kindly gave them an information about planktons in sea water.

\section{References}

[1] RILEY, G.A. and Gorgy, S. 19.18: Quantitative Studies of the Western North Atlantic. J. Mar. Res., 7, p. 100.

[2] Serwell, H. R. 1935: The Annual Organic Production and Nutrient Phosphorus Requirement in the Tropical Western North Atlantic. J. Cons. Int. Explor. Mer., 10, p. 20.

[3] Nielsen, E.S. 1952: The Use of Radio-active Carbon $\left(\mathrm{C}^{14}\right)$ for Measuring Organic Production in the Sea. J. du Conseil, 18, p. 117.

[4] KIgosirI, K. 1954: Determination of $\mathrm{C}^{14}$ by Lauritsen Type Electroscope with an Air Tight Ionization Chamber. Japan Analyst, 3, No. 4.

,, , 1953: The Separation of Isotopes by Countercurrent Gaseous Exchange Column (II)-Experimental Tests of the Theory. Bull. Chem. Soc. Jap., 26, p. 311.

[5] Saruilashi, K. 1953: On the Total Carbonaceous Matter and Hydrogen Ion Concentration in Sea Water. Pap. Met. Geophys., 3, p. 202.

[6] Saruhasili, K. 1953: The Chlorinity Determination of Sea Water by a Micro-analytical Method. Pap. Met. Geophys., 4, p. 90. 